\title{
Mental illness or mental distress; stigma and concealment in University students - a discussion paper
}

\author{
John James Power * \\ The School of Nursing and Midwifery, Queen's University Belfast, N Ireland, United Kingdom
}

Received: August 6, 2015

Accepted: September 29, $2015 \quad$ Online Published: October 19, 2015

DOI: $10.5430 /$ ijh.v2n1p29

URL: http://dx.doi.org/10.5430/ijh.v2n1p29

\begin{abstract}
This discussion paper addresses the issue of mental distress, sometimes mis- perceived or misinterpreted as mental illness. The focus is on positive psychology. Reflecting in part on a UK-based study with younger University students studying to health related degrees, nursing, midwifery and medicine $(\mathrm{N}=12)$, many of the students were apparently suffering dis-stress with disordered eating at least in part being used as a coping mechanism. However notwithstanding that they were at the end of their first year studies in health, a significant number of the students interpreted their approach to eating as a mental illness. Consequently, many within the study felt stigmatised and were reluctant to acknowledge certainly to the University health care authorities that there was an issue; perceiving both academic and career/professional consequences of mental health labelling. The paper approaches the issue of mental health from a health promoting perspective, reflecting against the theory of salutogenesis and its focus within the three dimensions of comprehensibility, manageability and meaningfulness as an approach to building resilience and managing stressors to better facilitate a sense of coherence. Complex manifestations of distress and poor coping mechanisms can in some cases be misinterpreted or miss perceived as mental illness. Promoting mental health and reducing the stigma of mental illness or the misperception of mental distress as mental illness, would need to be addressed in order to more effectively outreach certainly to younger University students who might be at risk. The focus should be on how better to promote their sense of coherence.
\end{abstract}

Key Words: Mental distress, Mental illness, Positive psychology, Sense of coherence

\section{INTRODUCTION AND BACKGROUND}

This paper discusses a range of issues in relation to university students' mental health, perceptions of mental illness, stigma and the perceived impact in relation to disclosure and academic/professional consequences. The focus is on a more positive approach to psychology rather than necessarily pathologising manifestations of distress as mental illness. By way of exploration it incorporates some data from a 2014 study of university students and patterns of disordered eating.

Disordered eating presents with disrupted and abnormal pat- terns of eating and attitudes to food that can form part of a range or spectrum of disturbed eating patterns and related behaviours. ${ }^{[1,2]}$ At one end of the spectrum this might present clinically with binge eating, bulimia nervosa or anorexia nervosa, or present as a "subclinical syndrome". ${ }^{[3-7]}$ There is significant and long-term risk both physically and psychologically to those struggling with disordered eating. ${ }^{[8,74]}$

The Royal College of Psychiatrists (RCP) report on the mental health of students in higher education ${ }^{[9]}$ suggests potentially significant patterns of disordered eating within

\footnotetext{
* Correspondence: John James Power; Email: j.power@qub.ac.uk; Address: The School of Nursing and Midwifery, Queen’s University Belfast, 97 Lisburn Road, Belfast, N.Ireland, BT9 7BL, United Kingdom.
} 
the undergraduate student population. Eisenberg, et al. ${ }^{[10]}$ concluded that possibly between $9 \%-13 \%$ of female students manifested significant sub-clinical disordered eating; this possibly correlates with an earlier study undertaken by Pokrajac Bulian ${ }^{[3]}$ suggesting that possibly $11.9 \%$ of female university students demonstrated behaviours which might be seen as "sub risk" for bulimia nervosa, in that study. Sanlier, et al. ${ }^{[6]}$ in a large mixed gender Turkish university student study suggests young females' were significantly at greater risk. The authors suggest that in this study $22.8 \%$ of the students were found to have eating disorders, with a significant proportion representing sub-clinically "mild form of eating disorder, i.e. an eating problem". However, in a most recent study from a Thai university the authors suggest that the prevalence of disordered eating behaviour was only evident in about $4.7 \%$ of the female undergraduate student population; this co-related with body image dissatisfaction, social pressures and academics stress. ${ }^{[11]}$ Dennard and Richards ${ }^{[12]}$ suggest within the literature review for their study that a potentially significant proportion of individuals experiencing disordered eating at "sub threshold levels" rather than being clearly symptomatic represented more of a continuum of disturbed patterns of eating.

The RCP Report ${ }^{[9]}$ suggest that universities could provide a unique opportunity to explore a range of health promoting approaches with undergraduate student, particularly within the context of the "healthy universities" initiative and the universities significant role and responsibility for "promoting health and well-being in students"; acknowledging that the "setting itself is crucially important in determining health and well-being". The context, setting and support available are significant elements with potential student distress ${ }^{[9,13,14]}$ and the possible emergence of disordered eating. ${ }^{[2,15,16]}$

Some of the literature relating to disordered eating places this within the realm of psychopathology and mental illness or suggests degrees of psychopathology for those affected by the experience. ${ }^{[6,8,17-24]}$ Stuart ${ }^{[24]}$ suggests that those living with mental illness are "amongst the most stigmatised groups in society". This perhaps reflects Goffman's ${ }^{[25]}$ earlier work on the damaging effects of stigma particularly in relation to mental illness and the impact on the individual's whole personhood; Eisenburg, et al. ${ }^{[10]}$ Wingfield, et al. ${ }^{[26]}$ suggest the issues with disordered eating can carry a significant stigma, including amongst the college student population. The British Psychological Society ${ }^{[27]}$ seems to favour the use of the term mental distress rather than mental illness, reflecting a significant proportion of sufferers lacking the coping resources to manage stressors; they suggested that a better approach to mental distress reflects the "overwhelming evidence that it is on a spectrum with normal experience" suggesting psychosocial factors as significantly causative.

Spectrum theory or a spectrum approach to "disorders" presents a model of gradation allowing a range of severity for condition such as eating disorders. ${ }^{[28,29]}$ The spectrum approach (ibid.) tends to limit the drawing together of symptoms within categories and the attachment of (sometimes rather negative) labels. The concept of a spectrum could be seen within the context of a continuum of health/illhealth ${ }^{[28,29]}$ reflective of Antonovsky's ${ }^{[30]}$ sense of coherence.

\subsection{Sense of coherence}

Sense of coherence (SOC): a concept incorporating key elements of comprehensibility, manageability and meaningfulness. These factors are built and sustained both individually but importantly collectively and socially. ${ }^{[30]}$ A SOC better enables the individual to live and indeed thrive despite the stressors of life, operate more holistically and in better communion with their world and society. ${ }^{[30,31]}$ A SOC is also reflected in (at least the individuals perception of) an enduring matrix and environment in which there is a degree of predictability/consistency and reasonable expectation of success (comprehensibility), together with sufficient resources to meet the challenges of that environment (manageability), and a sense of "meaningfulness" in terms of life and experience. ${ }^{[32,33]}$

Antonovsky ${ }^{[31,32]}$ suggests that with an over focus on pathology the human being and the context of the individual's distress (physical, psychological or combinations of both) tends to be ignored and managing the illness or more often suppressing the symptoms of the illness, remains the focus of the pathogenic model. Positive psychology presents the argument for identifying and enhancing protective factors and strengths of individuals, rather than the traditional focus on pathology and risk factors, as characterizing the future for the field of psychology and the health sciences. ${ }^{[34]}$ Positive psychology could therefore be seen more as a preventive health model rather than a model of disease and pathology. The pathogenic model functions more to a paradigm that seeks to remove or suppress stress (whether of a biological or of a psychosocial nature) whereas the salutogenic model seeks to more effectively understand and incorporate stress within the process of "holistic" emotional wellbeing. ${ }^{75,76]}$

Eisenburg, et al..$^{[10]}$ in a study with US university undergraduate and postgraduate students noted high incidence of disordered eating pathology with evidence of relatively low treatment seeking. The authors suggested that possible reasons for low treatment seeking might include the impact of stigma. Disordered eating whether a form of psychopathol- 
ogy or reflective of problems in living appears to carry a rather negative label and in some instances stigma. ${ }^{[5,26,35,36]}$ Wingfield et al. ${ }^{[26]}$ suggest that amongst university students disordered eating carries a stigma with bulimia nervosa carrying a significant stigmatised image of poor self-control. The authors note the sometimes negative impact of media portrayals in the sense of reinforcing potential stigma, and a sense amongst the general public of the individual's responsibility for their condition. Malterud and Solvang ${ }^{[37]}$ and Langeland and Wahl ${ }^{[38]}$ argue that the imposition of a mental ill-health label reduced an individual's sense of self. Ahern and Fisher ${ }^{[39]}$ suggest that labelling can present a recovery barrier impacting upon an individual's self-esteem and reducing early treatment seeking, and distorting the individual perspective particularly for those at risk. Substantially, the young university undergraduate suffering with or at risk from disordered eating is not experiencing a sufficient degree of coping and coherence in life: ${ }^{[40,41]}$ a sense of coherence is a key characteristic of wellness and the salutogenic model of health and wellbeing.

Reesnick, et al. ${ }^{[42]}$ and Resnick ${ }^{[43]}$ suggest that individual "protective" characteristics of the child or adolescent include high levels of self-esteem; a sense of being valued, wanted: having a religious or spiritual identity and a perception of longevity. Reimer ${ }^{[44]}$ suggests evidence of a decline in selfconfidence and self-esteem, increasing body image dysmorphia, increased evidence of disordered eating and higher rates of depression amongst young adolescent girls - although possibly boys are more likely to manifest behavioural problems. Resnick, et al. ${ }^{[42]}$ also suggest the possibility that stressors might impact as patterns of disordered eating, and might have more of a multiplier effect on young women than on young men (ibid). Reimer notes that risk and protective factors might differ across social and cultural boundaries. ${ }^{[44]}$ Again this study whilst not specifically testing the salutogenic model of health promotion, suggests a greater need to focus and support the students sense of coherence and particularly the "manageability" of their student lives and their sense of value and purposefulness (meaningfulness).

Gana $^{[45]}$ suggests that a reasonably developed SOC acts as a buffering effect between the individual and adverse experience/stressors. Individuals with a limited SOC might interpret life as rather chaotic, rather unpredictable, situations in which they can exert relatively poor control. Moksnes, et al., ${ }^{[46]}$ in a study involving both elementary (13 to 15 years) and secondary school students (16 to 19 years) in two counties of Norway, suggest that an enhanced SOC reflects in a more stable emotional response to stressors in adolescence and that young females appeared to be more at risk in terms of anxiety and potential states of depression.

\subsection{Stress and coping}

The first year as an undergraduate university student can evidently present significant stressors. ${ }^{[40,41,47,48]}$ Darling, et $a l .{ }^{[49]}$ explored students' stress and the influence of interpersonal relationships on a SOC. The authors suggest that coming to university was a high stress experience for many of the new students. Stressors particularly included establishing new relationships and academic challenges. The study underlines the importance of fostering a better SOC in the students, with programmes helping to cultivate a SOC, reflected in the structure of courses with material more sensitive to a SOC.

Chemers and Garcia ${ }^{[50]}$ suggest the powerful impact of the first year at university upon the undergraduate's self-esteem and ability to effectively adjust to university life both academically and socially. Sampson ${ }^{[51]}$ suggests that high levels of stress and stressors in university students can reflect in a range of behavioural pathology, including disordered eating patterns, and that it was important to understand how students deal with stress. Ball and Lee, ${ }^{[20]}$ Bertelli, et al. ${ }^{[52]}$ suggests that individuals with inadequate tolerance to stress (poor coping) may well be functioning at chronic levels of "overstress" including disrupted eating patterns. Therefore the arrival at university as a first year undergraduate can present significant stressors to the young student, ${ }^{[4]}$ can possibly impact more negatively and damagingly where the students SOC is limited, ${ }^{[49]}$ and stressors can impact on self-esteem and possibly stimulate disordered eating behaviours. ${ }^{[53]}$

\subsection{Coping skills as an undergraduate}

Coping both depends on the unique characteristics of the individual but also reflects into the structure of support, the matrix in which the individual functions, ${ }^{[54,55]}$ and an interaction between the stressor, the environment and the individual's perception/response. Antonovsky ${ }^{[32]}$ and Taylor ${ }^{[56]}$ suggest that stressors are not necessary concrete realities, but are perceptions of reality; social constructs that can therefore be reconstructed. The individual's personal assets qualities and strengths interact positively or negatively with factors reflecting the situation. ${ }^{[15]}$ Individuals who appear to have low resources for coping might be seen as rather fragile and vulnerable when confronted with stressors, by way of contrast those with significantly higher coping resources might be viewed as rather more resilient. ${ }^{[57]}$

Stuart ${ }^{[24]}$ suggests that with regards to mental health labelling and the possibility of resulting stigma this could be seen as significantly attaching to or arising from the diagnostic process and treatment processes within conventional psychiatry. Earlier work from critics of the medico/psychiatric paradigm of mental health such as Szasz ${ }^{[58,59]}$ and Scheff ${ }^{[60]}$ significantly challenged the conventional approach to psychiatric 
diagnosis and indeed a range of the treatments, arguing that at least in some cases this represented the pathologising of difference or deviance from accepted social norms; significant difference or problems in living were then reconstructed as mental-health conditions. Katsching ${ }^{[61]}$ questions the diagnostic criteria and the rationale for drawing together a series of behavioural and attitudinal presentations within diagnosable psychiatric conditions. This seems to echo some of the criticism advanced in relation to DSM 5 by the British Psychological Society. ${ }^{[27]}$ Importantly and as noted Eisenburg, et al. ${ }^{[10]}$ possibly suggest that the negative impact of a mental health stigma may reflect in low treatment seeking.

\section{THE STUDY}

A recent study undertaken at one of the large UK universities explored the issue of university students and disordered eating, seeking understanding of the student's perspective and how the University could better outreach to, facilitate and support students who might be at risk. Some of the data emerging related to student's perceptions of mental illness.

The sample comprised younger first year undergraduate students (aged 25 years and under) drawn from the School of Nursing and Midwifery and the School of Medicine ( $\mathrm{N}=$ 12). All students were first year undergraduates studying to significant health related degrees. Pilot work was undertaken in late 2012 and the formal study in the latter part of 2013 extending to spring 2014.

The study applied qualitative and phenomenological methodology within a salutogenic theoretic framework reflects the themes of comprehensibility, manageability and meaningfulness. Data was analysed thematically Phase I involved a narrative analysis of the open questions. Phase II involved thematic content analysis of the semi structured questions. The conceptual framework was drawn from the salutogenic model (Antonovsky ${ }^{[30,32]}$ ) addressing the key themes of (1) comprehensibility, (2) manageability and (3) meaningfulness. Ethical approval was obtained for the study and ethical principles and practice strictly applied with a potentially vulnerable group of students.

\section{Findings}

Within the core themes of comprehensibility and manageability some interesting data emerged in relation to student's perceptions of disordered eating and mental health.

\subsection{Comprehensibility}

This reflects the degree to which an individual comprehend significant issues and areas in life and can be reasonably assured of manageable predictability within those areas. ${ }^{[30,32]}$ Some of the students viewed emergent disordered eating as consequential upon "mis-perception" of stressors, mental dis-stress or problems in living:

"but the amount of people that present with disordered eating - sort of in the middle, you would put it down to just day to day ... they would be problems of living". $\mathrm{AO} 4$

However, a significant number of the students (8/12) interpreted disordered eating as reflective of mental illness;

"I sort of see it as a behavioural thing maybe, psychologically there's maybe something not right, ... but I think other people think they are crazy". DO2

"I see it as a mental health issue. Like I know now that I'm cognitively able to function, but when I was ill I just thought ... um ... another world". AO5

"it's a mental health condition that needs a bit more kick up the rear end ... and pleased on being granted a place at Queen's at 'not being passed off as a 'looper'". C1

"I think most things associated with mental illness carry a stigma ... I didn't think you could admit to having a problem like that, so I think people should be made aware before they start university, of that they can talk about it, and they aren't going to be stigmatised, because I didn't even think about talking to someone, until you brought up the interview... but I think that people would still have stigma towards that sort of mental side of things". AO4

\subsection{Manageability}

Manageability reflects the degree to which an individual perceives the resources and availability of resources to deal with the stressors in life. ${ }^{[30,32]}$ What was evident with a number of the students was there relative lack of external control-an external locus (7/12); and disordered eating as a means of controlling that stress $(9 / 12)$.

"I just see it as something I can control, because I think it's because I've had such a lack of control over a lot of my life, that now I just like having the food and exercise". A05

"I think it goes back to the whole 'everything else feels so out of order', and its gaining some sort on hold on everything that you can control ... it's the sort of thing ..." OB 1

"Um ... it sort of controlling, if you ever talk to anyone you feel light and food is taken out of the equation so you are able to get on with other stressful things". AO4 "I didn't feel as in control ... kind of restricted a bit more than...needed to control what is going on about you". AO8

"when I went to Queens and then I started my studies and was in quite a controlled environment and quite a 
stressful and quite studious environment I suppose my need to have something that I could sort of control myself ...” AO9

"It's like accomplishing something - something that you can set of yourself that you can do-it-yourself and you set your own standards and boundaries and your own goals as such. And then if you feel that you've achieved them it gives you that extra boost. It's that bit you can control. It does give you strength. It sort of fills an emptiness. A sense of purpose in such a busy world". A09

Some of the students talked about stress and its impact upon them:

"I think there's a lot more stressors in life, there's a lot more mental health issues because of the way we live, and because of the pressures of society. I think that's more contributing to it than social media ... I just think there is a lot more pressure on people, especially younger people". OB1

"I find it stressful, not so much the work, you know, trying to meet new people. I can be shy ... just worrying what other people think". A11

"I think it depends on how you cope with the stress, because I know things with myself ... financial worries, I'm struggling quite a bit for a degree, and that led me into stress and I was a bit concerned I was going down the route of becoming quite ill again, because it was an awful burden". OB1

"I don't think they have to or they always happen with everybody, I think some people have their good stress/positive stress set apart from the negative, but I need to work out how to do that". CI

"Yeah, I think whenever I'm stressed out about work, my eating would be worse, anxiety and stress". AO5

"Yeah. Completely. You don't think it at the time, but it does, like the past week has been fairly stable and ok, but for a couple of weeks before that I was really stressed and everything, and my eating was ridiculous ... you just thought I'd gone back in time five years ... but for me if I know I have X...Y...Z... to be done in the next few weeks, I have a small freak out inside and have a bing". C1

"I think I make it chaotic ... I'm quite a stressful person, I think about things too much. I worry about stuff a lot, so when I' $m$ in a state of stress...it affects what I eat. Definitely, because it would cause extra stress, and practical things such as financial issues". AO4

"Um ... I think I'd see it as a control when I can't control things ... It's not positive at all, I know it's not, otherwise

Published by Sciedu Press
I wouldn't be in this state, but I think sometimes I tell myself that it is if that makes sense". AO5

"I don't think I'm an exceptional sufferer, but it does feel like a lonely road ... At times, for example; this week...no... Next week...yes. Like...I won't go out with my friends because I can't face eating dinner, and then that's your social life for the week ruined, or not being able to enjoy things, and trying to hide things." CI

"At the start you think it is quite nice having their own little- it doesn't last very long you do feel quite lonely and isolated-people start commenting and saying things to you about it. But then they just go off and do their own thing and it doesn't seem to matter to ..." A09

AO8 had already been diagnosed with anorexia nervosa before her arrival at University, away from the family she was boarded in the university Halls of Residence. This seems to have added to her initial sense of separation and isolation. She describes her first few months at university and the experience of arriving back to University Halls after a day's teaching: "a lonely experience' with relatively little significant social contact between five o'clock until you went to bed." AO8

And whilst the new experience of learning can engage the student, the loneliness and isolation of not having solid consistent and supportive friendships can contribute stressfully.

\section{Discussion}

An analysis of the students' background narrative suggested poor coping mechanisms to stressful situations. A significant number perceived (or miss-perceived) disordered eating as mental illness. Consequently a number of the students were reticent to acknowledge that there were present or emerging problems and issues in this regard. They feared both the stigma of mental illness but also the academic and professional consequences they perceived as following on from disclosure. Consequently most of the students interviewed concealed the issue of disordered eating. It must be remembered that these were first year health care professionals that should have at least some insight to the nature of mental health and social distress.

Edwards and Beesling, ${ }^{[62]}$ Gana, ${ }^{[45]}$ Moksnes, et al. ${ }^{[46]}$ all suggest that a better developed sense of coherence reflects a more stable emotional response to stress and more positive mental health. A number of the students either directly in interview or from interpretation of the background narrative appeared to use disordered eating (at least in part) as a stress coping mechanism.

A significant number of the students associated disordered 
eating with mental illness, again this association is mirrored in some of the literature. ${ }^{[1,18,20]}$ A range of studies would seem to suggest that disordered eating represents a mental illness or suggests degrees of psychopathological symptoms, ${ }^{[6,8,17-22]}$ and is so classified within DSM-V. Whether this perception of mental illness is reflected in the students' reticence to acknowledge to tutors that there was an issue was not evident from this small study and the study did not explore this. However, as already noted there is debate within the literature as to what extent disturbed eating patterns represent mental illness; Katsching' ${ }^{[61]}$ questions the criteria used to diagnose disturbed eating patterns and the British Psychological Society ${ }^{[27]}$ underlines the need to acknowledge the impact of social context arguing for more focus upon the spectrum of health and on difference rather than disability. Again this approach is perhaps more reflective of a salutogenic model of health and wellbeing (Antonovsky 1996). ${ }^{[30]}$

\subsection{Coping}

Whilst the study did not specifically explore students stress coping mechanisms, a significant number of the students appeared to struggle with levels of stress and poor coping mechanisms. The effective management of stress reflects in both the individual's perception of the stress and in their ability to utilise effective coping skills, as key constituents of an effective sense of coherence. ${ }^{[4,46,63-65]}$ Chemers and Garcia $^{[50]}$ suggest significant impact on first-year university student's ability to effectively cope with the stresses of new university life. The inability to manage stress effectively (through more effective coping mechanisms) may reflect in patterns of disordered eating. ${ }^{[4,23,51]}$ Johnson $^{[33]}$ discusses the links between more effective stress coping and management and an individual's locus of control; an externalized locus being more significantly associated with less positive perceptions of stressors and the use of less effective stress coping mechanisms. However within this study, there appeared to be a significant correlation between limited coping strategies, perceptions of mental illness and perceptions of a negative response to disclosure. The general narrative within the context of discussing disordered eating was less than positive and probably focused more within the illness rather than the wellness spectrum of health.

With regards to Feeding and Eating Disorders (K00-07) the British Psychological Society (BPS) argue for less medicalisation of normal and natural responses to experiences. Medicalisation (they suggest) tends to have a rather negative impact, rather than accepting the individual presentation as "normal responses" "responses which undoubtedly have distressing consequences which demand helping resources, but which do not reflect illness is so much as normal individual variation". ${ }^{[27]}$ They argue that the classification of these conditions as mental illnesses ignores the context and social causatives of many of the problems. ${ }^{[27]}$ Cilliers $^{[66]}$ suggests that an enhanced sense of coherence can help the individual to address the unknown and sometimes threatening concerns that can populate the subconscious; an enhanced sense of coherence better allows the individual to select a strategy appropriate to deal with particular situations and stressors. Gropp, et al. ${ }^{[67]}$ suggest significant links between Antonovsky's sense of coherence, positive psychology and psychological wellness rather than a more pathological model of psychiatric morbidity.

Stress can be perceived both in a positive and challenging sense ${ }^{[13,68]}$ but can also present negatively, damagingly and impact significantly on a student's sense of coherence. ${ }^{[49]}$

\subsection{Concealment}

Fear of disclosure and possible impact on academic/professional undergraduate studies and future career prospects was evident both within the interviews and from the emergent narrative of the study. Although not specifically addressed within the study, these elements correlated with a significant number of the student's perceptions of the distressing condition as mental illness, rather than poor coping responses to stressors.

Antonovsky ${ }^{[32]}$ and Taylor ${ }^{[56]}$ both suggest that perception is a significant element in stress coping. McNeil, et al. ${ }^{[69]}$ argues that undergraduate students whose coping style predominates as avoidance with possible limited self-efficacy, may reflect in patterns of disordered eating as a distraction and a means of exerting control in stressful situations. The ability to cope effectively reflects both the characteristics of the individual but also the structural support available to them. ${ }^{[54,55]}$ The early demands of university life are better managed according to Abouserie ${ }^{[70]}$ with an internalised locus of control reflecting higher levels of self-esteem. Fontaine, et al., ${ }^{[71]}$ Beisley, et al. ${ }^{[72]}$ Heiman $^{[73]}$ and Darling, et al. ${ }^{[49]}$ all conclude that a more effective sense of control of events is reflected in a more stable sense of coherence.

\section{Conclusion}

In some cases, mental distress can be confused or missinterpreted as mental illness. Mental illness continues to carry a significant stigma with perceptions of possible life and career limitations. Stress coping is an area underdeveloped in young University students. Distressed can manifest in many ways, and in the case of some of the students within this small study group, possibly as disordered eating. Refocusing on mental health, rather than mental illness could 
help to lift stigma and encourage more openness, rather than concealment. Programmes could be more directed towards promoting health and well-being in the student population and upon building and sustaining a sense of coherence. Misperception of distress as mental illness, can have significant long-term and life limiting consequences.

\section{REFERENCES}

[1] Treasure JA. A Guide to the Medical Risk Assessment for Eating Disorders. Kings College London. South London and Maudsley NHS Trust. 2009.

[2] Quick VM, Byrd-Bredbenner C. Disturbed eating behaviours and associated psychographic characteristics of college students. Journal of Human Nutrition and Dietetics. 2013; 26(1): 53-63. PMID:23627697. http://dx.doi.org/10.1111/jhn.12060

[3] Pokrajac-Bulian A. Dissatisfaction with body and bulimic symptoms in the student population. Društvena istraživanja. 1998; 7(4-5): 581-601.

[4] Simon-Boyd G, Bieschke JK. Predicting eating disorder continuum groups: hardness and college adjustment. Poster Presentation Annual Conference of the American Psychological Association. 2003.

[5] Boyd C. Coping and Emotional Intelligence in Women with a History of Eating Disordered Behaviour. McNair Scholars Journal. 2006; 10(1): 4-12.

[6] Sanlier N, Yabanci N, Alyakut O. An evaluation of eating disorders among a group of Turkish university students. 2008; 51(3): 641-645. PMID:18584912. http://dx.doi.org/10.1016/j.appet. 200 8.05 .058

[7] Dissing AS, Bak NH, Pedersen LE, et al. Female medical students are estimated to have a higher risk for developing eating disorders than male medical students. Danish Medical Bulletin. 2011; 58(1): 207.

[8] Perieira RF, Alvarenga M. Disordered Eating: Identifying, Treating, Preventing and Differentiating it from Eating Disorders. Diabetes Spectrum. 2007; 5: 141-148. http://dx.doi.org/10.2337/dia spect.20.3.141

[9] Royal College of Psychiatrists. Mental Health and Students in Higher Education. 2011.

[10] Eisenberg D, Nicklett EJ, Roeder KM, et al. Eating Disorder Symptoms among College Students: Prevalence, Persistence, Correlates, and Treatment-seeking. Journal of American College Health. 2011; 59(8): 700-7. PMID:21950250. http://dx.doi .org/10.1080/0 7448481.2010 .546461

[11] Pattanathaburt P, Somrongthong R, Thianthai C. Prevalence of disordered eating behaviours, body image dissatisfaction, and associated factors among Thai female undergraduate students. International Journal of Health Promotion and Education. 2013; 51(3): 151-160. http://dx.doi.org/10.1080/14635240.2012.758883

[12] Dennard EE, Richards CS. Depression and coping in sub threshold eating disorders. Eating Behaviours. 2013; 14: 325-329. PMID:23910775. http://dx.doi.org/10.1016/j. eatbeh. 20 13.05 .011

[13] Friedlander LJ, Reid GJ, Shupak N, et al. Social support, self-esteem, and stress as predictors of adjustment to university among first year undergraduates. Journal of College Student Development. 2007; 48(3): 259-274. http://dx.doi.org/10.1353/csd.2007.0024

[14] El Ansari W, Clausen SV, Mabhala A, et al. How Do I Look? Body Image Perceptions among University Students from England and Denmark International. Journal of Environmental Research and Public Health. 2010; 7(2): 583-595.

Published by Sciedu Press
[15] Berg K, Frazier P, Sherr L. Change in eating disorder attitudes and behaviour in college students: prevalence and predictors. Eating Behaviours. 2009; 10: 137-142. PMID:19665094. http://dx.doi.o $\mathrm{rg} / 10.1016 / \mathrm{j}$. eatbeh .2009 .03 .003

[16] Beaukes M, Walker S, Esterhuyse K. The role of coping responses in the relationship between perceived stress and disordered eating in a cross-cultural sample of female university students. Stress and Health 2010; 26: 289-291. http://dx.doi.org/10.1002/smi.1296

[17] Collier DA, Treasure JL. The aetiology of eating disorders. British Journal of Psychiatry. 2004; 185: 363-365. PMID:15516542. http: //dx.doi.org/10.1192/bjp.185.5.363

[18] National Institute of Clinical Excellence, National Collaborating Centre for Mental Health. Eating Disorders: Core Interventions in the Treatment and Management of Anorexia. 2004.

[19] Southgate L, Tchanturia K, Treasuer J. Building a model of the aetiology of eating disorders by translating experimental neuroscience into clinical practice. Journal of Mental Health. 2005; 14(6): 553-566. http://dx.doi.org/10.1080/09638230500347541

[20] Ball K, Lee C. Relationships between psychological stress, coping and disordered eating: a review. Psychological Health. 2000; 14: 1007-1035. PMID:22175259. http://dx. doi .org/10.1080 /08870440008407364

[21] Wonderlich-Tierney AL, Vander Wal JS. The effects of social support and coping on the relationship between social anxiety and eating disorders. Eating Behaviour. 2010; 11(2): 85-91. PMID:20188291. http://dx.doi.org/10.1016/j. eatbeh.2009.10.002

[22] Sanftner JL. Quality of life in relation to psychosocial risk variables for eating disorders in women and men. Eating Behaviours. 2011; 12(2): 136-142. PMID:21385644. http://dx.doi .org/10.1016 /j. eatbeh.2011.01.003

[23] Micali N, Hagberg KW, Peterson I, et al. The incidence of eating disorders in the UK in 2000-2009: findings from the General Practice Research Database. 2013.

[24] Stuart H. Fighting the stigma caused by mental disorders: past perspectives, present activities and future directions. World Psychiatry. 2008; 7(3): 185-188. PMID:18836546.

[25] Goffman E. Stigma: Notes on the Management of Spoiled Identity. London: Prentice-Hall; 1963.

[26] Wingfield N, Kelly N, Serdar K, et al. University students' Perceptions of Individuals with Anorexia and Bulimia Nervosa. International Journal of Eating Disorders. 2011; 44(4): 369-375. PMID:21472755. http://dx.doi.org/10.1002/eat. 20824

[27] British Psychological Society Response to the American Psychiatric Association: DSM-5 Development. 2011.

[28] Patton GC. The spectrum of eating disorder in adolescence. Journal of Psychosomatic Research. 1988; 32(6): 579-84. http://dx. doi .org/10.1016/0022-3999 (88) 90006-2

[29] Maser JD, Akiskal HS. Spectrum concepts in major mental disorders. The Psychiatric Clinics of North America. 2002; 25(4): xi-xiii. http://dx.doi.org/10.1016/S0193-953X (02) 00034-5

[30] Antonovsky A. The salutogenic model as a theory to guide health promotion. Health Promotion International. 1996; 11: 11-18. http: //dx.doi.org/10.1093/heapro/11.1.11 
[31] Antonovsky A. Unravelling the mystery of health: how people manage stress and stay well. San Fransisco: Josey-Bass; 1987.

[32] Antonovsky A. Health, stress and coping. San Francisco: JosseyBass; 1979.

[33] Johnson M. Approaching the Salutogenesis of sense of coherence: The role of active self-esteem and coping. British Journal of Health Psychology. 2004; 9: 419-432. PMID:15296687. http://dx.doi .org/10.1348/1359107041557057

[34] Seligman MEP, Csikszentmihalyi M. Positive Psychology: An Introduction. American Psychologist. 2000; 55(1): 5-14. PMID:11392865 http://dx.doi.org/10.1037/0003-066X.55.1.5

[35] French SA, Leffert N, Story M, et al. Adolescent binge/purge and weight loss behaviours: Associations with developmental assets. Journal of Adolescent Health. 2001; 28(3): 211. http://dx . doi .org /10.1016/S1054-139X (00) 00166-X

[36] Fennig S, Hadas A, Itzhaky L, et al. Self-criticism is a key predictor of eating disorder dimensions among inpatient adolescent females. International Journal of Eating Disorders. 2008; 41(8): 762-5 PMID:18570191. http://dx.doi.org/10.1002/eat. 20573

[37] Malterud K, Solvang P. Vulnerability as a strength: why, when and how? Scandinavian Journal of Public Health. 2005; 33(66): 3-6. PMID:16214715. http://dx.doi .org/10.1080/14034950510 033291

[38] Langeland E, Wahl AK. The impact of social support on mental health service users sense of coherence: a longitudinal panel survey. International Journal of Nursing Studies. 2009; 46: 830837. PMID:19201408. http://dx.doi.org/10.1016/j.ijnur stu. 2008.12.017

[39] Ahern NR, Norris AE. Examining factors that increase and decrease stress in adolescent community college students. Journal of Paediatric Nursing. 2011; 26(6): 530-40. PMID:22055373. http: $/ /$ dx.doi.org/10.1016/j.pedn.2010.07.011

[40] Harvey L, Drew S. The first year experience: a review of the literature for the Higher Education Academy. The Higher Education Academy. 2006.

[41] DeHart T, Tennen H, Armeli S, et al. A diary study of implicit self-esteem, interpersonal interactions and alcohol consumption in college students. Journal of Experimental Social Psychology. 2009; 45(4): 720-730. PMID:20161219. http://dx.doi .org/10.1016 $/ j \cdot j$ esp. 2009.04.001

[42] Reesnick M, Dearman T, Blum R, et al. Protecting adolescence from harm; findings from the longitudinal study on adolescent health. Journal of the American Medical Association. 1997; 278: 823-832. http://dx.doi.org/10.1001/jama.1997.03550100049038

[43] Resnick MD. Protective Factors, Resiliency and Health and Youth Development. Adolescent Medicine: State of the Art Reviews. 2000; 11(1): 157-164.

[44] Reimer M. Gender risk and resilience in middle school context. Children and Schools. 2002; 24(1): 34-47.

[45] Gana K. Is sense of coherence a mediator between adversity and psychological well-being in adults? Stress and Health. 2001; 17 : 77-83. http://dx.doi.org/10.1002/smi. 882

[46] Moksnes UK, Espnes GA, Lillefjell M. Sense of coherence and emotional health in adolescents. Journal of Adolescence. 2012; 35: 433 441. PMID:21831417. http://dx.doi.org/10.1016/j. adole scence.2011.07.013

[47] Ramsay S, Jones E, Barker M. Relationship between Adjustment and Support Types: Young and Mature-Age Local and International FirstYear University Students. Higher Education. 2007; 54(2): 247-265. http://dx.doi .org/10.1007/s10734-006-9001-0

[48] Steinhardt M, Dolbier C. Evaluation of a resilience intervention to enhance coping strategies and protective factors and decrease symp- tomatology. Journal of American College Health. 2008; 56: 445 453. PMID:18316290. http://dx.doi.org/10.3200/JACH. 56 $.44 .445-454$

[49] Darling CA, McWey LM, Howard SN, et al. College student stress: the influence of interpersonal relationships on sense of coherence. Stress and Health. 2007; 23: 215-229. http://dx.doi.org/10. 1002/smi.1139

[50] Chemers MM, Hu L, Garcia BF. Academic self-efficacy and first year college student performance and adjustment. Journal of Educational Psychology. 2001; 93(1): 55-64. http://dx.doi.org/10.1037 10022-0663.93.1.55

[51] Sampson A. Stress and College/University Students. Berlin: Lambert Academic Publications; 2009.

[52] Bertelli S, Boccalari L, Centorame F, et al. The influence of stress on the relationship between cognitive variables and measures of eating disorders (in healthy female university students): a quasiexperimental study. Eating and Weight Disorders. 2008; 13(3): 142-8. PMID:19011372. http://dx.doi.org/10.1007/BF03327615

[53] Ruggiero GM, Bertelli S, Boccalari L, et al. The influence of stress on the relationship between cognitive variables and measures of eating disorders (in healthy female university students): a quasiexperimental study. Eating and Weight Disorders. 2008; 13(3): 142-8. PMID:19011372. http://dx.doi .org/10.1007/BF03327615

[54] Lazarus RS, Folkman S. Stress, appraisal, and coping. New York: Springer; 1984.

[55] Frydenberg E. Adolescent Coping: Theoretical and research perspectives. London: Routledge; 1997.

[56] Taylor S. Salutogenesis as a framework for child protection: literature review, Journal of Advanced Nursing. 2004; 54(6): 63-643. http://dx.doi.org/10.1046/j.1365-2648.2003.02954.x

[57] Peterson C. A primer in positive psychology. New York: Oxford University Press; 2006.

[58] Szasz T. The Myth of Mental Illness. American Psychologist. 1960; 15: 113-118. http://dx.doi.org/10.1037/h0046535

[59] Szasz T. Law, Liberty, and Psychiatry: An Inquiry into the Social Uses of Mental Health Practices. Syracuse University Press; 1989.

[60] Scheff TJ. Being mentally ill: A sociology theory. Chicago: Aldine; 1966.

[61] Katsching H. Are Psychiatrists and endangered species? Observations on internal and external challenges to the profession. World Psychiatry. 2010; 9(1): 21-28.

[62] Edwards D, Besseling E. Relationship between depression, anxiety, sense of coherence, social support and religious involvement in a small ruralcommunity affected by industrial relations conflict. South African Journal of Psychology. 2001; 31(4): 62.

[63] Pallant JF, Lae L. Sense of coherence, well being, coping and personality factors: Further evaluation of the sense of coherence scale. Personality \& Individual Differences. 2002; 33(1): 39-48. http://dx.doi.org/10.1016/S0191-8869(01) 00134-9

[64] Marais A, Stuart AD. The role of temperament in the development of Post-traumatic Stress Disorder amongst journalists. South African Journal of Psychology. 2006; 35: 89-105. http://dx.doi.org/1 $0.1177 / 008124630503500106$

[65] Fok SE, Chair SK, Lopez V. sense of coherence, coping and quality of life following a critical illness. Journal of Advanced Nursing. 2005; 49(2): 173-181. PMID:15641950. http://dx.doi.org/10. $1111 / j .1365-2648.2004 .03277 . x$

[66] Cilliers F. The Role of Sense of Coherence in Group Relations Training. Journal of Industrial Psychology. 2001; 27(3): 13-18. http://dx.doi.org/10.4102/sajip.v27i3.29 
[67] Gropp L, Geldenhuys D, Ne Visser D. Psychological Wellness Constructs: Relationships and Group Differences. South African Journal of Industrial Psychology. 2007; 33(3): 24-34.

[68] Walker J, Payne S, Smith P, et al. Psychology for Nurses and the Caring Professions. Maidenhead: OU Pres; 2012.

[69] Macneil L, Esposito-Smythers C. Mehlenbeck R, Weismoore. The effects of avoidance coping and coping self-efficacy on eating disorder attitudes and behaviors: a stress-diathesis model. Eating Behavior. 2012; 13(4): 293-6. PMID:23121777. http://dx.doi.org/10. 1016/j. eatbeh.2012.06.005

[70] Abouserie R. Sources and Levels of Stress in Relation to Locus of Control and Self-Esteem in University Students, Educational Psychology. 1994; 14(3): 323-330. http://dx.doi.org/10.1080/0 144341940140306

[71] Fontaine KR, Manstead ASR, Wagner H. Optimism, perceived control over stress and coping. European Journal of personality. 1993; 7: 267-281. http://dx.doi.org/10.1002/per.2410070407
[72] Beasley M, Thompson T, Davidson J. Resilience in response to life stress: effects of coping style and cognitive hardiness. Personality and Individual Differences. 2003; 34: 77-95. http://dx.doi.org /10.1016/S0191-8869(02)00027-2

[73] Heiman T. Examination of the Salutogenic Model, support resources, coping style, and stressors amongst Israeli University students, Journal of Psychology: Interdisciplinary and Applied. 2004; 138(6): 505-520. PMID:15612607. http://dx.doi .org/10.3200/JRLP. $138.6 .505-520$

[74] Beat Beating Eating Disorders. 2013. Available from: http://www.b-eat.co.uk/support-us/get-involved/ campaigning/university-campaign/

[75] Strümpher DJW. Salutogenesis: A new paradigm South Africa. Journal of Psychology. 1990; 20(4): 264-276.

[76] Strümpfer DJW. The origins of health and strength: from "salutogenesis" to "fortigenesis". South African Journal of Psychology. 1995; 25(2): 81-87. http://dx.doi.org/10.1177/008124639 502500203 